\title{
Photochemical transformation of zearalenone in aqueous solutions under simulated solar irradiation: Kinetics and influence of water constituents
}

\author{
Elissandro S. Emídio a, Vânia Calisto b, *, Mary Rosa R. de Marchi a , Valdemar I. Esteves ${ }^{\text {b, ** }}$ \\ a Analytical Chemistry Department, Chemistry Institute, São Paulo State University-UNESP, Araraquara, SP, 14801-970, Brazil \\ ${ }^{\mathrm{b}}$ Department of Chemistry and CESAM (Centre for Environmental and Marine Studies), University of Aveiro, Campus de Santiago, 3810-193, Aveiro, \\ Portugal
}

\section{H I G H L I G H T S}

- The transformation of ZEN has been studied under simulated solar irradiation.

- Conversion of trans- to cis-ZEN was observed predominantly during the irradiation.

- Half-lifes varied from 28 to 136 (natural waters) to 1777 min (deionized water).

- Influence of natural water constituents on the rate of photolysis was reported.

- First publication reporting the ZEN phototransformation in natural waters.

\section{A R T I C L E I N F O}

\section{Article history:}

Received 23 June 2016

Received in revised form

31 October 2016

Accepted 8 November 2016

Available online 18 November 2016

Handling Editor: Jun Huang

\section{Keywords:}

Mycotoxins

Phototransformation

Solar simulated irradiance

Natural waters

\begin{abstract}
A B S T R A C T
The presence of estrogenic mycotoxins, such as zearalenone (ZEN), in surface waters is an emerging environmental issue. Little is known about its phototransformation behavior, which may influence its environmental fate. In this context, the phototransformation of ZEN was investigated in pure water, river water and estuarine water using simulated sunlight irradiation. Kinetic studies revealed that two concomitant processes contribute to the fate of ZEN under solar irradiation: photoisomerization and photodegradation. This phototransformation followed a pseudo-first order kinetics. ZEN degrades quickly in natural waters and slowly in deionized water, with half-lives ( $\left.\mathrm{t}_{1 / 2}\right)$ of $28 \pm 4$ min (estuarine water), $136 \pm 21 \mathrm{~min}$ (river water) and $1777 \pm 412 \mathrm{~min}$ (deionized water). The effects of different water constituents on the phototransformation of ZEN in aqueous solution have been assessed $\left(\mathrm{NaCl}, \mathrm{Ca}^{2+}\right.$, $\mathrm{Mg}^{2+}, \mathrm{Fe}^{3+}, \mathrm{NO}_{3}^{-}$and oxalate ions, synthetic seawater, $\mathrm{Fe}(\mathrm{III})$-oxalate and $\mathrm{Mg}(\mathrm{II})$-oxalate complexes, humic acids, fulvic acids and XAD-4 fraction). In the presence of synthetic seawater salt ( $\mathrm{t}_{1 /}$ $2=18 \pm 5 \mathrm{~min})$ and $\mathrm{Fe}(\mathrm{III})$-oxalate complexes $\left(\mathrm{t}_{1 / 2}=61 \pm 9 \mathrm{~min}\right)$, the transformation rate increased considerably in relation to other water constituents tested. The solution $\mathrm{pH}$ also had a considerable effect in the kinetics with maximum transformation rates occurring around $\mathrm{pH}$ 8.5. These results allow us to conclude that phototransformation by solar radiation can be an important degradation pathway of ZEN in natural waters.
\end{abstract}

() 2016 Elsevier Ltd. All rights reserved.

\section{Introduction}

Mycoestrogens are naturally occurring estrogens produced as secondary metabolites by several molds of the Fusarium genus that

\footnotetext{
* Corresponding author.

** Corresponding author

E-mail addresses: vania.calisto@ua.pt (V. Calisto), valdemar@ua.pt (V.I. Esteves).
}

colonize a wide variety of crops, including wheat, barley, oats, rice and corn (Kinani et al., 2008). Amongst the well-known mycoestrogens are zearalenone (ZEN) and its metabolites which have estrogenic activities similar to those of natural estrogens (estrone and estriol) (Le Guevel and Pakdel, 2001) and higher than those of many notorious synthetic endocrine disruptors, such as bisphenol A, DDT and atrazine (Coldham et al., 1997; Sforza et al., 2006).

Although ZEN possesses a relatively low acute toxicity (oral LD 
50 values of $>2000-20,000 \mathrm{mg} \mathrm{kg}^{-1}$ b.w.) after oral administration in mice, rats and guinea pigs, ZEN causes pronounced estrogenic symptoms including vulvovaginitis, uterine enlargement, prolonged or interrupted estrus, infertility in farm animals and it is occasionally implicated in hypoestrogenic syndromes in humans (Zinedine et al., 2007). In addition, it is suspected to be a triggering factor for central precocious puberty development in girls (Massart et al., 2008). Experiments exposing zebrafish (Danio rerio) to ZEN confirm its estrogenic potential to influence sexual differentiation and reproduction. Decreased frequency of spawning and fecundity and stimulation of plasma vitellogenin were observed after 21 day exposure of adult zebrafish to $0.1-1 \mu \mathrm{g} \mathrm{L}^{-1}$ of ZEN (Schwartz et al., 2010).

Because of the high stability of ZEN during milling, food processing and heating, among others, it is reasonable to assume that this compound is persistent in the environment (Ryu et al., 2003). The occurrence of mycoestrogens has been extensively studied in food and feed products, however fewer studies focused on their occurrence in the natural aqueous environment (Jarosová et al., 2015). Potential aqueous environmental contamination pathways by mycoestrogens include: (1) runoff and drainage water from fields cultivated with infected plants, (2) runoff from livestock facilities or fields receiving livestock manure applications, and (3) human excretions via wastewaters (Schenzel et al., 2012). Several studies have examined the occurrence of ZEN with concentrations in surface waters ranging from 1.4 to $96.0 \mathrm{ng} \mathrm{L}^{-1}$ (Gromadzka et al., 2009; Kolpin et al., 2014), in groundwater between $<0.3$ and $0.5 \mathrm{ng} \mathrm{L}^{-1}$ (Gromadzka et al., 2009) and in influents and effluents of wastewater treatment plants (WWTP) in the range of 1.0-19.8 ng L ${ }^{-1}$ (Gromadzka et al., 2015; Lagana et al., 2001), providing evidence of both diffuse and point sources of this compound into the environment. Runoffs from agricultural activities and sites downstream of the WWTP's effluent discharge have been identified as high risk factors for mycoestrogen exposure.

Although often ignored, ZEN can occur in two configurations. The double bond between $C_{11}$ and $C_{12}$ (Fig. 1) may isomerize from the trans to the cis configuration (Drzymala et al., 2014). Since the 1970s it is known that this isomerization can easily be achieved by artificial UV light or sunlight (Peters, 1972). The structure of cis-ZEN was primarily confirmed by nuclear magnetic resonance and recently by X-ray crystallography (Köppen et al., 2012b). The cisZEN is chemically stable and retains its configuration in biological systems. Reports on the occurrence of cis-ZEN as natural product (Muñoz et al., 1989; Richardson et al., 1985) may be due to exposure of the trans-isomer to light. The cis-isomer has been described in edible oils, raw grains and especially wet ground maize for feeding. Isomerization occurs at high extent under sunlight, but the cis-trans ratio may largely vary depending on the environmental conditions
(Brezina et al., 2013; Köppen et al., 2012a). Due to analytical limitations, data about the occurrence of the two isomers are still scarce and a preliminary risk assessment study has never been done.

Recently, Drzymala et al. (2015) compared the estrogenicity of eleven different ZEN congeners using the E-Screen assay. Overall, a change in the configuration from trans to cis retains significant estrogenic activity. In the cited work, cis-ZEN was slightly more active $\left(\mathrm{EC}_{50}=0.41 \mathrm{nM}\right)$ than trans-ZEN $\left(\mathrm{EC}_{50}=0.62 \mathrm{nM}\right)$.

Among the several environmental degradation processes (abiotic/biotic), photodegradation is one of the most important for determining the fate of contaminants in aquatic environments (Chowdhury et al., 2011). Solar phototransformation of organic compounds in aquatic environments may occur either by direct or indirect photolysis within the photic zone. Direct photolysis occurs due to the absorbance of photons of certain energy by the substrate and depends on both the rate of light absorption and the reaction quantum yield of the excited state (Chowdhury et al., 2010). On the other hand, indirect photolysis occurs via light absorption by photosensitizers, some of the most important being dissolved organic matter (DOM), nitrate/nitrite ions, and Fe(III)/Fe(II)-organic substance complexes (Zhan, 2009). Excited photosensitizers generate singlet oxygen $\left({ }^{1} \mathrm{O}_{2}\right), \mathrm{OH}$ radicals $(\cdot \mathrm{OH})$, DOM-derived peroxy radicals $\left(\mathrm{ROO}^{*}\right)$, triplet-state DOM $\left({ }^{3} \mathrm{DOM}^{*}\right)$, solvated electrons, $\left(e_{\mathrm{aq}}^{-}\right)$and other photoreactants that can react with the compounds of interest and therefore influence their environmental fate, persistence and ecological risk in natural water systems (Lin and Reinhard, 2005).

The objective of this study was to determine the kinetics of the phototransformation of ZEN in natural waters and to understand the effects of water constituents on its photolysis. Up to now, the photochemical behavior and especially the contribution of photolysis to the degradation of this compound in environmental water samples have not been studied.

\section{Material and methods}

\subsection{Chemicals}

ZEN (Empirical formula: $\mathrm{C}_{18} \mathrm{H}_{22} \mathrm{O}_{5}$, CAS registry number: 1792492-4) solid standard was purchased from Sigma-Aldrich (St. Louis, MO, USA) with purity higher than $99 \%$. Methanol (MeOH) for HPLC analysis was of HPLC-grade and purchased from Fisher Scientific (Ottawa, Ontario, Canada). Tropic Marin ${ }^{\circledR}$ (synthetic seawater salt, contains all major and minor elements, for a total of 70 elements, to reproduce the natural concentrations found in the ocean) was purchased from Marinus Inc. (Long Beach, CA). All other reagents used for solutions were reagent grade and used without further purification. Deionized water was obtained from a Millipore

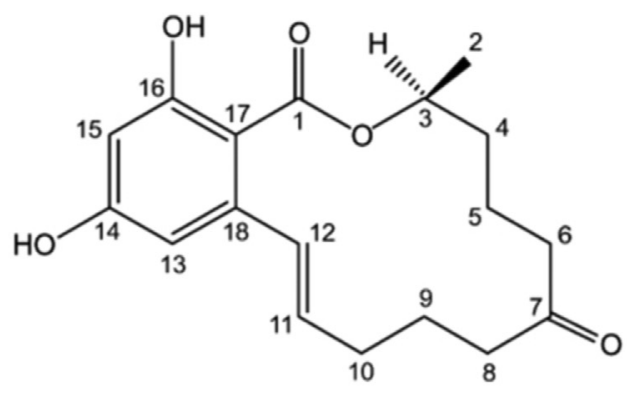

trans-zearalenone

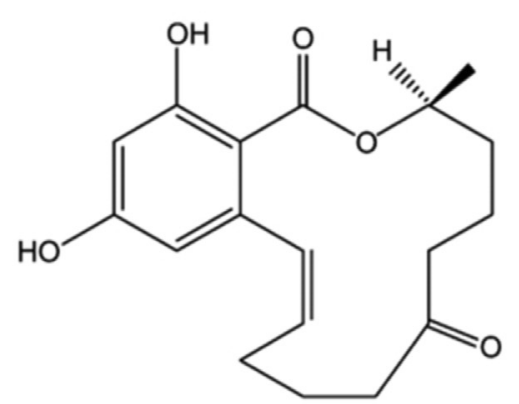

cis-zearalenone

Fig. 1. Chemical structures of trans-zearalenone and cis-zearalenone. 
purification system (Milli-Q plus 185). Stock solutions of ZEN were prepared in deionized water at concentration of $2.7 \mathrm{mg} \mathrm{L}^{-1}$. The solution was stored at $4{ }^{\circ} \mathrm{C}$ in sealed flasks, protected from light to prevent any degradation. Irradiated samples were prepared by diluting the ZEN stock solution to a final concentration of $100 \mu \mathrm{g} \mathrm{L}^{-1}$. The stock solution was also used to prepare calibration standard solutions.

\subsection{Water samples}

Surface water samples were collected in October 2015. One surface water sample (estuarine origin) was collected from Ria de Aveiro located in the urban city center of Aveiro, (Cais da Fonte Nova, Ria de Aveiro, Aveiro, Portugal). This sampling site is typically known to have high contents of organic matter and salinity. The other tested surface water sample was collected from Rio Novo do Príncipe (located in a rural agricultural area of Aveiro, Portugal), which is situated in the confluence of the Vouga River with the Ria de Aveiro coastal lagoon. Salinity, $\mathrm{pH}$, total carbon (TC), inorganic carbon (IC), dissolved organic carbon (DOC) and total iron contents were measured for the surface water samples. These techniques are described below in Section 2.4.2.

Samples were collected in $1 \mathrm{~L}$ glass bottles, previously washed with dilute alkaline soap solution, distilled water, acetone, evaporated to dryness, and rinsed with sampling water before sample collection. All samples were immediately filtered through $0.22 \mu \mathrm{m}$ PVDF filter membranes (Red Analytical, UK) to remove any particles and microorganisms and stored in the dark at $4{ }^{\circ} \mathrm{C}$. The water samples were used within a period of time as short as possible (less than 2 weeks).

\subsection{Irradiation experiments}

\subsubsection{Solar simulator device}

Photodegradation experiments were carried out under simulated solar radiation using a Solarbox 1500 (CO.FO.ME.GRA, Milano, Italy), equipped with a $1500 \mathrm{~W}$ Xenon lamp and outdoor UV filters that allowed the transmission of light only at wavelengths above $290 \mathrm{~nm}$. During the irradiation experiment, the irradiance of the lamp was kept constant at $55 \mathrm{~W} \mathrm{~m}^{-2}(290-400 \mathrm{~nm})$, corresponding to $550 \mathrm{~W} \mathrm{~m}^{-2}$ for the whole spectrum $(290-800 \mathrm{~nm})$. A multimeter (CO.FO.ME.GRA, Italy) equipped with a black standard temperature sensor and a UV 290-400 nm large band sensor was used to monitor the temperature and irradiance levels, respectively. The temperature of the device chamber was maintained by an air cooled system and irradiation uniformity was guaranteed by a parabolic reflector chamber. A scheme of the irradiation apparatus is presented in Fig. S1 (in Supplementary Data).

\subsubsection{Kinetics experiments}

ZEN aqueous solutions, with $100 \mu \mathrm{g} \mathrm{L}^{-1}$ concentration, were irradiated in triplicate using $25 \mathrm{~mL}$ quartz tubes (internal diameter of $1.5 \mathrm{~cm}$ and height of $20 \mathrm{~cm}$ ). For each set of experiments, dark controls were also performed in triplicate, foiled several times with aluminum paper. The quartz tubes were suspended inside the irradiation chamber using a home-made metallic holder which assured that samples were homogeneously irradiated.

Phototransformation kinetics experiments of ZEN were performed in the following aqueous matrices: deionized water, freshwater and estuarine water. Quartz tubes (for samples and dark controls) were filled with $15 \mathrm{~mL}$ of solution. Aliquots $(1 \mathrm{~mL})$ were collected between 0 and $180 \mathrm{~min}$ for freshwater and estuarine water samples, and between 0 and $1680 \mathrm{~min}$ for the deionized water sample. Aliquots were stored at $4{ }^{\circ} \mathrm{C}$ (refrigerator) until analysis.
Other irradiation experiments were performed testing the role of different natural water constituents, on the phototransformation of ZEN. These experiments were performed in deionized water by adding (separately) $\mathrm{Ca}^{2+}$ (added salt, $\mathrm{CaCl}_{2}$ ), $\mathrm{Mg}^{2+}$ (added salt, $\mathrm{MgCl}_{2}$ ), $\mathrm{Fe}^{3+}$ (added salt, $\mathrm{FeCl}_{3}$ ), $\mathrm{NO}_{3}^{-}$(added salt, $\mathrm{NaNO}_{3}$ ) and oxalate ions (added salt, $\mathrm{Na}_{2} \mathrm{C}_{2} \mathrm{O}_{4}$ ), $\mathrm{NaCl}$, synthetic seawater, $\mathrm{Fe}(\mathrm{III}$ )oxalate and $\mathrm{Mg}(\mathrm{II})$-oxalate complexes, and different humic substances (humic acids (HA), fulvic acids (FA) and XAD-4 fraction). Concentrations for each constituent were set according to naturally-occurring levels in waters. HA, FA and XAD-4 fraction were extracted and isolated from a local riverine water sample (Esteves et al., 1995). Humic substances were used to simulate natural dissolved organic matter. Ultrasonication was used for the solubilization of humic acids in water (30 min, at $80 \mathrm{~W}$ ). Sodium phosphate buffer solution $(0.01 \mathrm{M}, \mathrm{pH} 7.3)$ was added in order to eliminate the effect of $\mathrm{pH}$ variations, except in the presence of HA, FA and XAD-4 fraction. The phosphate buffer solution was also evaluated separately without adding any constituent (blank test). The influence of $\mathrm{pH}$ on ZEN transformation was studied in sodium phosphate buffers $(0.01 \mathrm{M})$ at different $\mathrm{pH}$ values $(5.5 ; 6.5 ; 7.5$ and 8.5) during a 180 min irradiation time.

Experimental kinetic data were fitted to a pseudo-first order kinetic model by non-linear regression analysis. In this context, the concentration values for ZEN were represented as a function of time $C(t)=C_{0} e^{-k t}$, where $C_{0}$ and $C$ are the concentrations of ZEN at time zero and reaction time $t(\min ), k$ is the first order transformation rate constant $\left(\mathrm{min}^{-1}\right)$, and the half-life of ZEN was determined as $t_{1 / 2}=\ln (2) k^{-1}$. Data analysis was carried out using GraphPad Prism software, version 5.03.

\subsection{Analytical methods}

\subsubsection{Analysis of ZEN samples}

Quantitative analysis of ZEN was performed on a Shimadzu Prominence HPLC system (Kyoto, Japan) equipped with a DGU$20 \mathrm{~A} 5$ on-line degasser, LC-20AD solvent delivery module, CTO10ASVP column oven, and RF-20A XS fluorescence detector. Separations were carried out with a New $\mathrm{ACE}^{\circledR}$ C18 column-PFP $(150 \mathrm{~mm} \times 4.6 \mathrm{~mm}, 5 \mu \mathrm{m})$ connected to an $\mathrm{ACE}^{\circledR} 5 \mathrm{C} 184.6 \mathrm{~mm}$ i. d. guard column. The mobile phase consisted of a mixture of $\mathrm{MeOH}$ and ultra-pure water $(75: 25, v / v)$, at a flow rate of $0.5 \mathrm{~mL} \mathrm{~min}{ }^{-1}$ with an injection volume of $20 \mu \mathrm{L}$. Mobile phase constituents were filtered through $0.2 \mu \mathrm{m}$ polyamide membrane filters (Whatman Inc., USA). Detection was performed using a Shimadzu RF-20A XS Prominence fluorescence detector, set to excitation and emission wavelength of $275 \mathrm{~nm}$ and $460 \mathrm{~nm}$, respectively. The column temperature was maintained at $30^{\circ} \mathrm{C}$, and the detector flow cell at $35^{\circ} \mathrm{C}$. The used HPLC method of analysis satisfactorily separates the trans- from cis-zearalenone $\left(t_{R}=8.1 \mathrm{~min}\right.$ and $t_{R}=8.6 \mathrm{~min}$, respectively).

Two calibration curves were obtained for ZEN quantification in the concentration range of $2-75 \mu \mathrm{g} \mathrm{L}^{-1}$ and $5-150 \mu \mathrm{g} \mathrm{L}^{-1}$. The first curve was used for the quantification of the lowest ZEN concentrations and the second curve was used for the establishment of linearity over the specified range. Each concentration was measured in triplicate. Limits of detection (LOD) and quantification (LOQ) were determined by the calibration curve method according to International Conference on Harmonization (ICH) guidelines (ICH, 2005), for the curve considering the concentration range of $2-75 \mu \mathrm{g} \mathrm{L}{ }^{-1}$. LOD was defined as $3.3 \times(\sigma) / S$ and LOQ was computed as $10 \times(\sigma) / S$, where $\sigma$ is the standard deviation of the y-intercepts and $S$ is the slope of the calibration curve. LOD and LOQ values were 1 and $4 \mu \mathrm{g} \mathrm{L}^{-1}$, respectively. The calibration linearity for ZEN was established in the range between LOQ and $150 \mu \mathrm{g} \mathrm{L}^{-1}$.

The UV-visible spectra of ZEN solutions were obtained with a 
T90 + UV/VIS Spectrophotometer (PG Instruments Ltd.) in a $1 \mathrm{~cm}$ path length rectangular quartz cuvette. Spectra were measured over the wavelength range of 270 and $820 \mathrm{~nm}$.

\subsubsection{Chemical characterization of environmental water samples}

The concentrations of dissolved total carbon (TC) and dissolved inorganic carbon (IC) were determined using a Shimadzu TOCVCPN analyzer. The dissolved organic carbon (DOC) content of the samples was calculated as the difference between TC and IC. The $\mathrm{pH}$ was measured using a pH meter (Ecoscan, EUTECH. Instruments, Singapore). The total iron concentration was determined using an atomic absorption spectrometer AAnalyst 100 (Perkin Elmer, Norwalk, CT, EUA).

\section{Results and discussion}

\subsection{Identification of trans/cis-zearalenone}

In our phototransformation experiments, ZEN was eluted as two separate peaks, which corresponded to trans-ZEN and cis-ZEN $\left(t_{R}=8.1 \mathrm{~min}\right.$ and $t_{R}=8.6 \mathrm{~min}$, respectively). The identification was carried out in part based on the retention time using HPLC elution on $\mathrm{C}_{18}$ column under isocratic conditions $\left(\mathrm{MeOH}: \mathrm{H}_{2} \mathrm{O}\right)$. The isomer with the shorter retention time is assigned the trans configuration (trans-ZEN) and that with the longer retention time is assigned the cis configuration (cis-ZEN). These results (HPLC elution) are in agreement with Köppen et al. (2012a) and Brezina et al. (2013). Additional verification was achieved with simulated sunlight irradiation of aqueous solutions (in pure water) of ZEN because the trans-cis transformation is known to be promoted by light (Peters, 1972). Apart from the identification of the two isomers during the irradiation, no other fluorescent byproducts were detected.

\subsection{Phototransformation in pure water}

Phototransformation of ZEN was investigated in deionized water, irradiating the solution during $28 \mathrm{~h}$ (1680 min). In the dark controls, no obvious transformation of ZEN was observed, indicating that the decay by microbiological, thermal, or hydrolytic processes was negligible during the time of the photolysis experiments. Thus, the observed concentration decay was assumed to be due only to photolysis.

The results obtained allowed the identification of two distinct phototransformation phenomena: (1) conversion of trans- to cisZEN; (2) phototransformation of trans-ZEN and cis-ZEN. During the initial period of the irradiation, the decrease of trans-ZEN was accompanied by an increase of cis-ZEN (monitored as the cis-ZEN peak area in the chromatograms). The cis-ZEN peak area reached a maximum after 180 min of irradiation time, corresponding to about $50.2 \%$ of transformation of trans-ZEN. After $180 \mathrm{~min}$ of irradiation time a decrease of both trans- and cis-ZEN was observed. The graphical representation of the concentration of trans-ZEN along the irradiation (Fig. 2(A) and (B)) suggests that the two phenomena described above result into two different decay kinetics: the first part is marked mainly by the trans/cis photoisomerization, while the second part of the kinetics is dominated by photodegradation of trans-ZEN (and also by the photodegradation of cis-ZEN). Consequently, the experimental data of phototransformation of transZEN were divided into two parts (from 0 to $180 \mathrm{~min}$ and from $180 \mathrm{~min}$ to $1680 \mathrm{~min}$ ) and each part was separately fitted to a pseudo-first order kinetic model. In Fig. 2(B), the curve was extrapolated between 0 and $180 \mathrm{~min}$ by assuming that the kinetics of photodegradation of trans-ZEN in this time interval is equal to that observed after $180 \mathrm{~min}$ of irradiation time. The values of rate constants and determination coefficient were $k_{o b s}=(4.3 \pm 0.6) \times 10^{-3} \mathrm{~min}^{-1}$ and $\mathrm{R}^{2}=0.977$ (mainly isomerization), $k_{o b s}=(3.9 \pm 0.7) \times 10^{-4} \mathrm{~min}^{-1}$ and $\mathrm{R}^{2}=0.965$ (mainly degradation), respectively, which evidences that the irradiation period dominated by photoisomerization has a rate constant that is 10 times higher than the subsequent period, dominated by photodegradation processes. Therefore, the contribution of the photodegradation of trans-ZEN to the decrease of total ZEN concentration during the first part of the irradiation, dominated by the isomerization process, was considered to be negligible.

This behavior (isomerization/degradation) is consistent with that observed by Köppen et al. (2012a) for ZEN in corn oil. The naturally occurring trans-ZEN is assumed to be transformed by ultraviolet irradiation to the more stable cis-ZEN, causing both isomers to co-occur. Cis-ZEN was reported in edible oils and wet maize when exposed to UV-light (UVA 315-380 nm) (Brezina et al., 2013; Köppen et al., 2012a). As observed by Avetta et al. (2014) for dimethomorph isomerization, it is acceptable to assume that a photostationary equilibrium is reached between cis- and trans-ZEN and that a steady-state dynamic constant ratio is maintained under irradiation.

\subsection{Phototransformation in natural waters}

Similarly to phototransfomation of ZEN in pure water, the results were divided into two phenomena occurring at two different kinetic rates (isomerization and degradation). The pseudo-first order kinetic model was adequate to describe the experimental data in both cases ( $\mathrm{R}^{2}$ values ranged from 0.985 to 0.995$)$. Within the experimental error, no obvious transformation of ZEN was observed in the dark during the experiments. Similarly to deionized water, there was a noticeably faster transformation (photoisomerizarion) in the first $15 \mathrm{~min}$ (river water) and $30 \mathrm{~min}$ (estuarine water) of irradiation followed by a slow transformation up to 180 min (photodegradation). Phototransformation (isomerization and photodegradation) plots of ZEN in the tested natural waters are depicted in Fig. 3. In Fig. 3 (A2) and (B2), photodegradation plots were extrapolated between the initial time and $30 \mathrm{~min}$ for river water and $15 \mathrm{~min}$ for estuarine water, supposing that the rate of the photodegradation of the trans-ZEN was equal before and after the given time.

The phototransformation rate of ZEN decreased in the following order: estuarine $>$ river $>$ deionized water illustrating a strong dependence on the composition of the irradiated media. Compared with pure water, natural waters contain optically active substances, which are prone to the generation of some active species (e.g., $\cdot \mathrm{OH}$ and ${ }^{1} \mathrm{O}_{2}$ ) contributing to the indirect photodegradation of ZEN under sunlight irradiation. Table 1 describes some physicochemical characteristics of these natural waters.

Half-lifes (degradation) decreased from $1777 \pm 412 \mathrm{~min}$ (deionized water) to $136 \pm 21 \mathrm{~min}$ (river water) and $28 \pm 4 \mathrm{~min}$ (estuarine water). These half-life times are strictly dependent on the experimental conditions used during the irradiation experiments (namely irradiance level and lamp spectrum). To transform the obtained results into data with environmental relevance, the half-life times of ZEN were converted into units equivalents to summer sunny days (SSD). Taking into consideration that the total energy reaching the ground in a summer cloudless day $\left(45^{\circ} \mathrm{N}\right.$ latitude) is $7.5 \times 10^{5} \mathrm{~J} \mathrm{~m}^{-2}$, one summer sunny day (SSD) will correspond to $3.8 \mathrm{~h}$ of irradiation (Calisto et al., 2011). By employing this conversion, it is possible to better estimate the half-life time of ZEN in real conditions. According to the obtained results, this compound can persist in the environment for between $0.12 \pm 0.02$ and $8 \pm 2$ SSD (Table 2).

The faster phototransformation of ZEN in the two natural waters compared to that observed in deionized water (half-lives of 13-63 

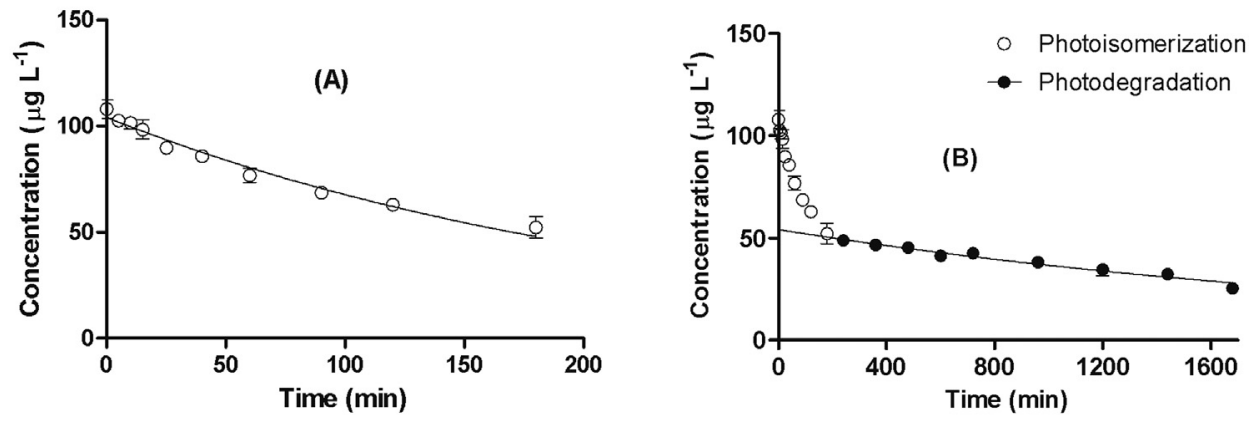

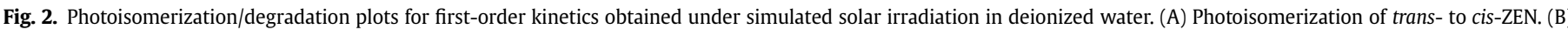
Photodegradation of trans-ZEN. Shown error bars are standard deviations $(n=3)$.
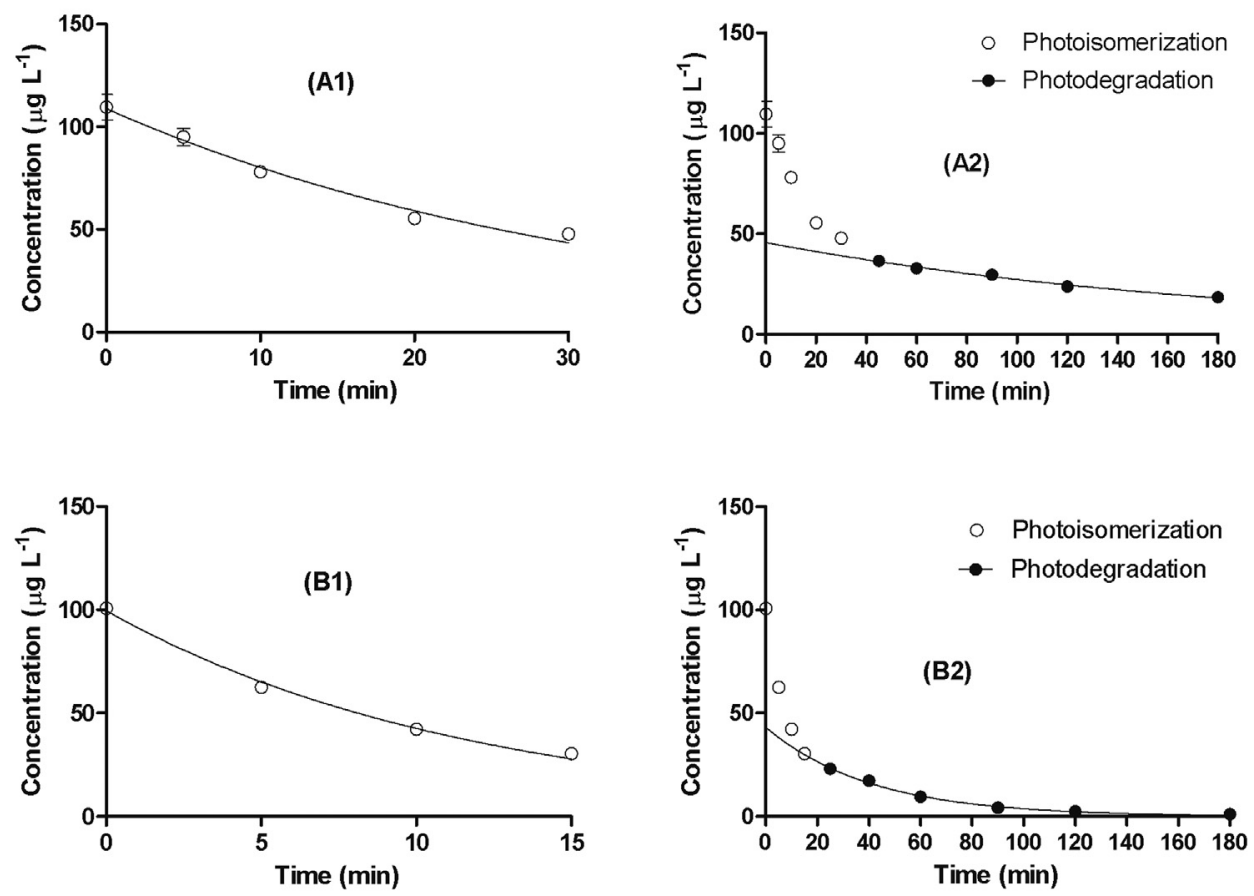

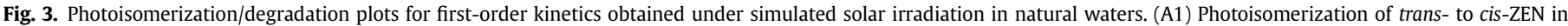

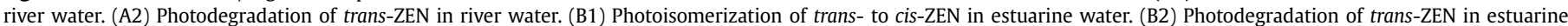
water. Shown error bars are standard deviations $(n=3)$.

Table 1

Physico-chemical characteristics of natural waters.

\begin{tabular}{|c|c|c|c|c|c|c|}
\hline Sample & $\mathrm{pH}$ & Salinity (\%o) & $\mathrm{TC}\left(\mathrm{mg} \mathrm{L}^{-1}\right)$ & $\mathrm{IC}\left(\mathrm{mg} \mathrm{L}^{-1}\right)$ & $\mathrm{DOC}\left(\mathrm{mg} \mathrm{L}^{-1}\right)$ & $\mathrm{Fe}_{\text {tot }}\left(\mathrm{mg} \mathrm{L}^{-1}\right)$ \\
\hline Estuarine water (Ria Aveiro) & 7.3 & 23 & 33.7 & 29.3 & 4.4 & b.q ${ }^{a}$ \\
\hline Riverwater (Rio Novo do Principe) & 7.7 & b.d $\mathrm{d}^{\mathrm{b}}$ & 8.0 & 4.8 & 3.2 & b. $q^{\mathrm{a}}$ \\
\hline
\end{tabular}

a Below quantification limit $\left(0.1 \mathrm{mg} \mathrm{L}^{-1}\right)$.

b Below detection limit.

Table 2

Pseudo-first-order rate coefficients for the phototransformation of ZEN in river and estuarine water.

\begin{tabular}{|c|c|c|c|c|c|}
\hline Sample & $\mathrm{R}^{2}$ & $\mathrm{k}_{\mathrm{iso}}\left(\min ^{-1}\right)$ & $\mathrm{k}_{\mathrm{deg}}\left(\min ^{-1}\right)$ & $\mathrm{t}_{1 / 2}(\mathrm{~min})$ & $\mathrm{t}_{1 / 2}(\mathrm{SSD})$ \\
\hline Deionized water & $0.965-0.977$ & $(4 \pm 1) \times 10^{-3}$ & $(4 \pm 1) \times 10^{-4}$ & $1777 \pm 412$ & $8 \pm 2$ \\
\hline River water & $0.985-0.989$ & $(3 \pm 1) \times 10^{-2}$ & $(5 \pm 1) \times 10^{-3}$ & $136 \pm 21$ & $0.6 \pm 0.1$ \\
\hline Estuarine water & $0.994-0.995$ & $(8 \pm 2) \times 10^{-2}$ & $(24 \pm 4) \times 10^{-3}$ & $28 \pm 4$ & $0.12 \pm 0.02$ \\
\hline
\end{tabular}


times lower) is expected to be primarily due to oxidation reactions triggered by the reactive species generated by natural photosensitizers, such as humic substances, transition metals, nitrate or nitrite.

Previous studies have pointed out that some aquatic constituents (e.g., dissolved organic matter (DOM), nitrate, bicarbonate, halides) can affect the photolysis of organic pollutants (Zhou et al., 2015). However, it is still unclear whether ZEN can be susceptible to these or other factors under irradiation. In the next step, studies were conducted to evaluate the rates of ZEN phototransformation and the influence of some estuarine water constituents (note that higher transformation rate of ZEN was observed in the estuarine water sample), which could accelerate or retard the photolytic process (Table 1).

\subsection{Effects of some water constituents on zearalenone phototransformation}

Natural water constituents are often used in controlled experiments with the goal of determining their specific influence in indirect photolysis (i.e., which photosensitizing species are involved) (Challis et al., 2014). In previous studies, humic acids, $\mathrm{Cl}^{-}, \mathrm{Br}^{-}, \mathrm{I}^{-}$, $\mathrm{Fe}(\mathrm{III}), \mathrm{NO}_{3}^{-}$, and $\mathrm{HCO}_{3}^{-}$were observed to accelerate, inhibit or have minor effect on the photolysis rate of organic contaminants (Ge et al., 2009, 2010; Li et al., 2011; Li et al., 2014).

Under simulated sunlight with different water constituents, degradation was observed throughout the $180 \mathrm{~min}$ of irradiation time. The rate of phototransformation of ZEN varied from $(4 \pm 1) \times 10^{-3}$ to $(39 \pm 17) \times 10^{-3} \mathrm{~min}^{-1}$ with half-life times between $18 \pm 5 \mathrm{~min}$ and $172 \pm 25 \mathrm{~min}$ (Table 3 ). The isomerization of trans- to cis-ZEN was also observed for the irradiation with all the evaluated constituents.

ZEN transformation rate was much higher $\left(\mathrm{k}=(39 \pm 17) \times 10^{-3} \mathrm{~min}^{-1}, \mathrm{t}_{1 / 2}=18 \pm 5 \mathrm{~min}\right)$ in synthetic seawater compared to solutions with other water constituents (Table 3 ), presumably due to the presence of natural photo-sensitizers in seawater. Sensitized photolysis of target compounds in seawater depends on the formation, and subsequent reactivity of reactive intermediates (indirect photolysis), such as singlet oxygen $\left({ }^{1} \mathrm{O}_{2}\right)$, hydroxyl radical $\left(\mathrm{HO}^{\bullet}\right)$, triplet excited dissolved organic matter $\left({ }^{3} \mathrm{DOM}^{*}\right)$ and halide radicals $\left(\mathrm{X}^{\cdot}, \mathrm{X}_{2^{-}}{ }^{-}\right)$(Glover et al., 2014). Compounds such as triclosan (Aranami and Readman, 2007), carbofuran (Campbell et al., 2004) and carbamazepine (Chiron et al., 2006) have increased degradation in saltwater in comparison to freshwater, which was attributed to the formation of halide radicals. $\mathrm{Al}$ Housari et al. (2010) found that $\mathrm{HO} \cdot{ }^{1} \mathrm{O}_{2}$, and chromophoric dissolved organic matter triplet state concentrations were higher in an estuarine water compared to freshwater.

Besides synthetic seawater, experiments with the addition of [Fe(III)]/[oxalate] $(0.4 / 6.0 \mu \mathrm{M})$ in deionized water resulted in the second largest increase in the transformation rate of ZEN (Table 3). After 180 min of irradiation time, 83\% of ZEN transformation was achieved. In sunlit surface waters, photochemical reactions of oxalate complexes with $\mathrm{Fe}(\mathrm{III})$ can produce $\mathrm{Fe}(\mathrm{II})$ and a series of reactive oxygen species (ROS) such as $\mathrm{O}_{2}{ }^{-}, \mathrm{HO}_{2}{ }^{\circ}, \mathrm{H}_{2} \mathrm{O}_{2}$ and $\mathrm{HO}$. The resulting production of $\mathrm{OH}$ radicals is very significant as they can oxidize a wide variety of natural and anthropogenic organic and inorganic substances (Liu et al., 2010). For example, the phenolic ring of estrogens is a crucial component of their potential to scavenge free radicals, and it might be readily oxidized by ROS (Zhou et al., 2004). However, differently from laboratory experiments with pure species, in natural waters $\cdot \mathrm{OH}$ would be scavenged by DOM and, in brackish waters, by bromide as well. Photo-bleaching of DOM by halides can destroy the chromophores necessary to produce ${ }^{3} \mathrm{DOM}^{*}$ and, without this precursor, the $\cdot \mathrm{OH}$ induced degradation is decreased.

The study of the effects of Fe(III) and oxalate ions separately resulted in half-lives similar to those obtained in deionized water, confirming specifically that is the interaction between $\mathrm{Fe}(\mathrm{III})$ and oxalate ions which increased the transformation rate of ZEN. However, the combination of magnesium and oxalate ions did not result in the same effect as the $\mathrm{Fe}(\mathrm{III})$-oxalate complexes. In this case, unlike iron, the transformation rate with $\mathrm{Mg}(\mathrm{II})$-oxalate was slower than the isolated effect of $\mathrm{Mg}^{2+}$ in aqueous solution.

It is worth noting that the ZEN transformation rates did not show remarkable differences in the presence of the different fractions of DOM (humic acids, fulvic acids and XAD-4 fraction) in comparison with some other water constituents (Table 3 ). These results are in agreement with a previous study published by Qu et al. (2012) for ZEN metabolites, at pH 7.0, where $\alpha$-zearalanol loss was observed in all solutions in the presence of $5 \mathrm{mg} \mathrm{L}^{-1}$ of DOM, with the greatest rate of decay being observed for soil humic acid $\left(\mathrm{t}_{1 / 2} \sim 3 \mathrm{~h}\right.$ and $\left.\mathrm{k}=0.214 \pm 0.009 \mathrm{~h}^{-1}\right)$ with simulated sunlight.

Overall, some water constituents had no influence on the transformation rate constant compared to deionized water, including $\mathrm{Fe}(\mathrm{III})$, nitrate, oxalate ions and $\mathrm{Mg}(\mathrm{II})$-oxalate. Despite the relevant transformation for ZEN in estuarine water and synthetic seawater, a $\mathrm{NaCl}$ solution (salinity $=23 \%$ ) did not show the same effect, i.e., salinity alone does not explain the increase of the phototransformation rate for estuarine water in comparison to river water. The participation of other reactive species that were not investigated here cannot be ruled out.

Table 3

Kinetic parameters for the phototransformation of zearalenone in different aqueous solutions.

\begin{tabular}{|c|c|c|c|}
\hline Matrix $^{a}$ & $\mathrm{k}, \min ^{-1}$ & $\mathrm{t}_{1 / 2}, \min$ & $\mathrm{R}^{2}$ \\
\hline Deionized water & $(4 \pm 1) \times 10^{-3}$ & $161 \pm 4$ & 0.977 \\
\hline $\mathrm{NaCl}$ salinity $(\% 0)=23$ & $(6 \pm 1) \times 10^{-3}$ & $107 \pm 18$ & 0.983 \\
\hline Synthetic sea water salt salinity $(\% 0)=23$ & $(39 \pm 17) \times 10^{-3}$ & $18 \pm 5$ & 0.955 \\
\hline Phosphate buffer $(0.01 \mathrm{M})$ & $(6 \pm 1) \times 10^{-3}$ & $121 \pm 28$ & 0.969 \\
\hline Fulvic acids ( $\left.9 \mathrm{mg} \mathrm{L}^{-1}\right)$ & $(6 \pm 1) \times 10^{-3}$ & $111 \pm 24$ & 0.976 \\
\hline $\mathrm{XAD}-4\left(9 \mathrm{mg} \mathrm{L}^{-1}\right)$ & $(6 \pm 1) \times 10^{-3}$ & $118 \pm 24$ & 0.978 \\
\hline Humic acids ( $9 \mathrm{mg} \mathrm{L}^{-1}$ ) & $(6 \pm 1) \times 10^{-3}$ & $127 \pm 21$ & 0.985 \\
\hline $\mathrm{Ca}^{2+}\left(9.2 \mathrm{mg} \mathrm{L}^{-1}\right)$ & $(5 \pm 1) \times 10^{-3}$ & $130 \pm 21$ & 0.986 \\
\hline $\mathrm{Mg}^{2+}\left(24.1 \mathrm{mg} \mathrm{L}^{-1}\right)$ & $(8 \pm 1) \times 10^{-3}$ & $91 \pm 17$ & 0.978 \\
\hline $\mathrm{Fe}^{3+}\left(0.1 \mathrm{mg} \mathrm{L}^{-1}\right)$ & $(4 \pm 1) \times 10^{-3}$ & $161 \pm 26$ & 0.984 \\
\hline $\mathrm{NO}_{3}^{-}\left(0.7 \mathrm{mg} \mathrm{L}^{-1}\right)$ & $(5 \pm 1) \times 10^{-3}$ & $151 \pm 24$ & 0.986 \\
\hline [Fe(III)]/[Oxalate] 0.4/6.0 ( $\mu \mathrm{M})$ & $(11 \pm 2) \times 10^{-3}$ & $61 \pm 9$ & 0.987 \\
\hline Oxalate $(6.0 \mu \mathrm{M})$ & $(4 \pm 1) \times 10^{-3}$ & $172 \pm 25$ & 0.977 \\
\hline$\left[\mathrm{Mg}^{2+}\right] /[$ Oxalate] $100 / 6.0(\mu \mathrm{M})$ & $(4 \pm 1) \times 10^{-3}$ & $154 \pm 33$ & 0.984 \\
\hline
\end{tabular}

\footnotetext{
${ }^{\mathrm{a}}$ Except for humic substances, all matrices were added a sodium phosphate buffer solution $\left(0.01 \mathrm{~mol} \mathrm{~L}^{-1}\right)$.
} 


\subsection{Influence of $\mathrm{pH}$ on phototransformation of zearalenone}

In comparison with some other phenolic compounds it can be presumed that deprotonated ZEN reacts faster than the undissociated compound (Neamtu and Frimmel, 2006). The study of the $\mathrm{pH}$ effect revealed that after 180 min of irradiation at $\mathrm{pH} 5.5$ and $\mathrm{pH}$ 8.5 , $55 \%$ and $72 \%$ of ZEN was transformed, respectively, which showed a considerable increase in phototransformation when the medium was more basic. This is probably due to the fact that in alkaline medium the molar absorption coefficients of the dissociated ZEN are slightly higher than at acidic pH (Li et al., 2015).

Because ZEN has a $\mathrm{pK}_{\mathrm{a} 1}$ value of approximately 7.6, it occurs in the neutral form at acidic $\mathrm{pH}$, whereas the corresponding phenolate anion occurs in solution at $\mathrm{pH} 7.0$ (in equilibrium with the protonated form) and predominates at pH 9.0 (Gajęcka et al., 2011). Therefore, both the protonated form and the phenolate are present in natural waters. The results obtained in the experiments performed at different environmentally relevant $\mathrm{pH}$ values are summarized in Fig. 4.

\subsection{Determination of the direct photolysis quantum yield for zearalenone}

The efficiency of a phototransformation process can be expressed in terms of quantum yield $(\phi)$, which is the ratio between the total number of molecules of the compound transformed by a chemical reaction per total moles of photons absorbed (Leifer, 1988). Quantum yields serve as a much better predictor of direct photolytic fate than just simply rate constants and half-lives; however, fewer studies tend to measure them as their determination is more complex. Direct photolysis quantum yields measure the efficiency with which a compound breaks down upon absorption of light. This property should be independent of the light source over a single electronic transition (absorption band) of a compound. Therefore, the quantum yield is essential for predictive and comparative purposes (Challis et al., 2014). In real aquatic environments, however, there are a wide variety of absorbing species that can indirectly contribute to the degradation of organic compounds. In this context, a direct photolysis quantum yield cannot be determined but, instead, one can define an overall reaction quantum yield that takes into account all the photo-induced reactions that result in the transformation of the target compound.

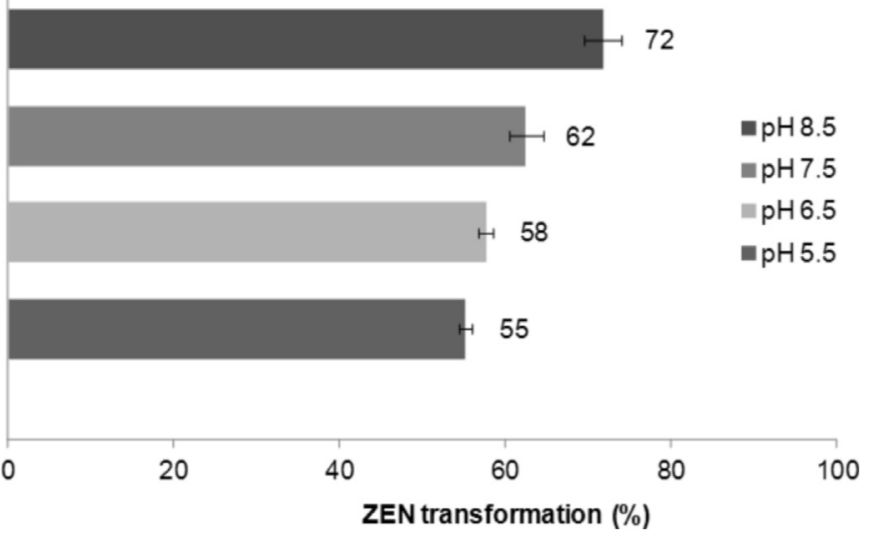

Fig. 4. Effect of $\mathrm{pH}$ on the phototransformation of ZEN. Conditions: irradiation time, $180 \mathrm{~min} ; 100 \mu \mathrm{g} \mathrm{L}^{-1}$ of ZEN in sodium phosphate buffers.
The quantum yield for the photolysis of ZEN in ultrapure, estuarine and riverine water was determined as an overall average over the lamp emission range (290-800 nm). Accordingly, the ZEN average quantum yield ( $\phi$ ave $)$ was calculated using Eq. (1) (Calisto et al., 2011):

$\phi_{\text {ave }}=\frac{C_{0} k}{\sum I_{\lambda \mathrm{i}}^{0} \times\left(1-10^{\varepsilon_{\lambda \mathrm{i} \times \mathrm{b} \times \mathrm{C}_{0}}}\right)}$

where $k$ is the apparent first order degradation constant $\left(\mathrm{s}^{-1}\right), C_{0}$ is the initial concentration of ZEN in solution $\left(\mathrm{mol} \mathrm{L}^{-1}\right), I^{0}{ }_{\lambda i}$ is the lamp

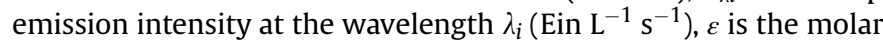
absorbivity of ZEN at $\lambda_{i}\left(\mathrm{~L} \mathrm{~mol}^{-1} \mathrm{~cm}^{-1}\right)$ and $\mathrm{b}$ is the path length inside the photoreactor $(\mathrm{cm})$ (diameter of the cylindrical photoreactor, $1.5 \mathrm{~cm}$ ). The lamp emission spectrum, as given by the manufacturer, is presented on Fig. S2 (Supplementary data).

An average quantum yield of $9.3 \times 10^{-5}, 6.5 \times 10^{-4}$ and $1.7 \times 10^{-4}$ over the wavelength range of $290-800 \mathrm{~nm}$, was obtained in pure, river and estuarine water, respectively, under simulated solar irradiation. No data for similar experimental conditions were published in the literature concerning ZEN phototransformation.

\subsection{Environmental significance of the results}

This research indicates that ZEN will be degraded significantly in the euphotic zone of surface waters. However, the phototransformation in the environment might be slower due to factors such as turbidity and coloring of the water (which would reduce the intensity of sunlight, an effect that is partially eliminated in laboratory experiments by water filtration) and also due to the height of the water column which also affects significantly the penetration of sunlight. The data presented here do not account for the light attenuation in the water column and other sitespecific factors. However, the photodegradation of ZEN can be foreseen based on these data, especially in shallow, clear water (where less sunlight attenuation occurs) and under strong irradiation.

Under environmental conditions, direct photolysis is expected to be a minor pathway for ZEN degradation. On the other hand, indirect photolysis is likely to be the main phototransformation pathway. However, the persistence of ZEN depends greatly on the water constituents, such as dissolved organic matter, estuarine water salts or $\mathrm{Fe}(\mathrm{III})$-oxalate complexes.

The half-lives measured in natural waters suggest that phototransformation is a potentially significant degradation process for ZEN. The phototransformation of ZEN was rapid in the natural waters (river and estuarine waters), with a half-life of less than one SSD. However, the high transformation rates might be compensated for by the continuous introduction of ZEN into the environment by release from infected plants, manure applications from exposed livestock, human waste via wastewater treatment plants and effluent from food-processing plants. This caveat is supported by the actual occurrence of ZEN in water bodies as shown in Section 1.

In a future work, we intend to identify the transformation products for ZEN and consider the potential ecotoxicological risks associated with their formation. Moreover, it is important to evaluate the degradation kinetics of cis-ZEN, which is unknown, since it appeared to be the main transformation product of trans-ZEN in environmental conditions. This study was not performed due to the lack commercially available cis-ZEN standards. Indeed, cis-ZEN is about as potent as trans-ZEN in terms of estrogenicity. 


\section{Conclusions}

Environmental contamination by estrogenic mycotoxins has been detected in natural waters, mostly through wastewater facilities, agricultural applications of animal waste and runoff and drainage water from agricultural fields. The present study demonstrates that the phototransformation of ZEN in natural waters (river and estuarine water) by simulated sunlight is much faster than in deionized water (with half-life times ranging from $0.12 \pm 0.02$ to $8 \pm 2 \mathrm{SSD}$, respectively), indicating that indirect photolysis is a major degradation pathway of this contaminant. The first step of the phototransformation is the fast conversion of transZEN into cis-ZEN which occurs when trans-ZEN undergoes both direct and indirect photolysis. Apart from the photoisomerization, photodegradation of trans-ZEN also occurred but at a slower rate.

A tentative evaluation of the environmental water constituents which are mainly responsible for this acceleration of the ZEN phototransformation in river and estuarine waters revealed an appreciable synergistic effect between $\mathrm{Fe}(\mathrm{III})$ and oxalate (ratio $1: 15)$. ZEN phototransformation is also significantly accelerated in the presence of seawater salts. However, this increase cannot be explained by the salinity alone. Additional studies are required to investigate the phototransformation products of ZEN and other metabolites, and to examine their effects on organisms living in contaminated aquatic environments.

\section{Acknowledgements}

Elissandro S. Emídio gratefully acknowledge the partial financial support and PhD grant ("Ciências sem Fronteiras" CNPq program reference number $233160 / 2014-0$ ) for this work. Thanks are also due for the financial support to CESAM (UID/AMB/50017/2013), to FCT/MEC through national funds, and the co-funding by the FEDER, within the PT2020 Partnership Agreement and Compete 2020. Vânia Calisto thanks Fundação para a Ciência e Tecnologia (FCT) for her postdoctoral grant (SFRH/BPD/78645/2011).

\section{Appendix A. Supplementary data}

Supplementary data related to this article can be found at http:// dx.doi.org/10.1016/j.chemosphere.2016.11.042.

\section{References}

Al Housari, F., Vione, D., Chiron, S., Barbati, S., 2010. Reactive photoinduced species in estuarine waters. Characterization of hydroxyl radical, singlet oxygen and dissolved organic matter triplet state in natural oxidation processes. Photochem. Photobiol. Sci. 9, 78-86.

Aranami, K., Readman, J.W., 2007. Photolytic degradation of triclosan in freshwater and seawater. Chemosphere 66, 1052-1056.

Avetta, P., Marchetti, G., Minella, M., Pazzi, M., De Laurentiis, E., Maurino, V., Minero, C., Vione, D., 2014. Phototransformation pathways of the fungicide dimethomorph ((E,Z) 4-[3-(4-chlorophenyl)-3-(3,4-dimethoxyphenyl)-1-oxo2-propenyl morpholine), relevant to sunlit surface waters. Sci. Total Environ. 500-501, 351-360.

Brezina, U., Kersten, S., Valenta, H., Sperfeld, P., Riedel, J., Danicke, S., 2013. UVinduced cis-trans isomerization of zearalenone in contaminated maize. Mycotoxin Res. 29, 221-227.

Calisto, V., Domingues, M.R.M., Esteves, V.I., 2011. Photodegradation of psychiatric pharmaceuticals in aquatic environments e kinetics andphotodegradation products. Water Res. 45, 6097-6106.

Campbell, S., David, M.D., Woodward, L.A., Li, Q.X., 2004. Persistence of carbofuran in marine sand and water. Chemosphere 54, 1155-1161.

Challis, J.K., Hanson, M.L., Friesen, K.J., Wong, C.S., 2014. A critical assessment of the photodegradation of pharmaceuticals in aquatic environments: defining our current understanding and identifying knowledge gaps. Environ. Sci. Process. Impacts 16, 672-696.

Chiron, S., Minero, C., Vione, D., 2006. Photodegradation processes of theantiepileptic drug carbamazepine, relevant to estuarine waters. Environ. Sci. Technol. 40, 5977-5983.

Chowdhury, R.R., Charpentier, P., Ray, M.B., 2010. Photodegradation of estrone in solar irradiation. Ind. Eng. Chem. Res. 49, 6923-6930.

Chowdhury, R.R., Charpentier, P., Ray, M.B., 2011. Photodegradation of 17 $\beta$-estradiol in aquatic solution under solar irradiation: kinetics and influencing water parameters. J. Photochem. Photobiol. A 219, 67-75.

Coldham, N.G., Dave, M., Sivapathasundaram, S., McDonnell, D.P., Connor, C., Sauer, M.J., 1997. Evaluation of a recombinant yeast cell estrogen screening assay. Environ. Health Perspect. 105, 734-742.

Drzymala, S.S., Herrmann, A.J., Maul, R., Pfeifer, D., Garbe, L.A., Koch, M., 2014. In vitro phase I metabolism of cis-zearalenone. Chem. Res. Toxicol. 27, 1972-1978.

Drzymala, S.S., Binder, J., Brodehl, A., Penkertc, M., Rosowskib, M., Garbed, L.-A., Kocha, M., 2015. Estrogenicity of novel phase I and phase II metabolites of zearalenone and cis-zearalenone. Toxicon 105, 10-12.

Esteves, V.I., Cordeiro, N.M.A., Duarte, A.C., 1995. Variation on the adsorption efficiency of humic substances from estuarine waters using XAD resins. Mar. Chem. $51,61-66$.

Gajęcka, M., Zielonka, Ł., Dąbrowski, M., Gajęcki, M., 2011. Threats resulting from the presence of zearalenone in water. Med. Wet. 67, 643-646.

Ge, L., Chen, J., Qiao, X., Lin, J., Cai, X., 2009. Light-source-dependent effects of main water constituents on photodegradation of phenicol antibiotics: mechanism and kinetics. Environ. Sci. Technol. 43, 3101-3107.

Ge, L., Chen, J., Wei, X., Zhang, S., Qiao, X., Cai, X., Xi, Q., 2010. Aquatic photochemistry of fluoroquinolone antibiotics: kinetics, pathways, and multivariate effects of main water constituents. Environ. Sci. Technol. 44, 2400-2405.

Glover, C.M., Mezyk, S.P., Linden, K.G., Rosario-Ortiz, F.L., 2014. Photochemical degradation of Corexit components in ocean water. Chemosphere 111, 596-602.

Gromadzka, K., Waśkiewicz, A., Goliński, P.. Świetlik, J., 2009. Occurrence of estrogenic mycotoxin - zearalenone in aqueous environmental samples with various NOM content. Water Res. 43, 1051-1059.

Gromadzka, K., Waśkiewicz, A., Swietlik, J., Bocianowski, J., Goliński, P., 2015. The role of wastewater treatment in reducing pollution of surface waters with zearalenone. Arh. Hig. Rada Toksikol. 66, 159-164.

International Conference on Harmonization, 2005. Validation of Analytical Procedures: Text and Methodology Q2 (R1). http://www.ich.org/fileadmin/Public Web_Site/ICH_Products/Guidelines/Quality/Q2_R1/Step4/Q2_R1_Guideline. pdf (Accessed 17 May 2016).

Jarosová, B., Javurek, J., Adamovský, O., Hilscherová, K., 2015. Phytoestrogens and mycoestrogens in surface waters-Their sources, occurrence, and potential contribution to estrogenic activity. Environ. Int. 81, 26-44.

Kinani, S., Bouchonnet, S., Bourcier, S., Porcher, J.-M., Aït-Aïssa, S., 2008. Study of the chemical derivatization of zearalenone and its metabolites for gas chromatography-mass spectrometry analysis of environmental samples. J. Chromatogr. A 1190, 307-315.

Kolpin, D.W., Schenzel, J., Meyer, M.T., Phillips, P.J., Hubbard, L.E., Scott, T.M., Bucheli, T.D., 2014. Mycotoxins: diffuse and point source contributions of natural contaminants of emerging concern to streams. Sci. Total Environ. 470, 669-676.

Köppen, R., Riedel, J., Proske, M., Drzymala, S., Rasenko, T., Durmaz, V., Weber, M., Koch, M., 2012a. Photochemical trans-/cis-isomerization and quantitation of zearalenone in edible oils. J. Agric. Food Chem. 60, 11733-11740.

Köppen, R., Riedel, J., Emmerling, F., Koch, M., 2012b. (3S,11Z)-14,16-Dihy-droxy-3methyl-3,4,5,6,9,10-hexa-hydro-1H-2-benz-oxacyclo-tetra-decine $\quad 1,7(8 \mathrm{H})$ dione (cis-zearalenone): a redetermination. Acta Crystallogr. 68, o832.

Lagana, A., Fago, G., Marino, A., Santarelli, D., 2001. Development of an analytical system for the simultaneous determination of anabolic macrocyclic lactones in aquatic environmental samples. Rapid Commun. Mass Spectrom. 15, 304-310.

Le Guevel, R., Pakdel, F., 2001. Assessment of oestrogenic potency of chemicals used as growth promoter by in-vitro methods. Hum. Reprod. 16, 1030-1036.

Leifer, A., 1988. The Kinetics of Environmental Aquatic Photochemistry: Theory and Practice. American Chemical Society, Washington, DC.

Li, Y., Niu, J.F., Wang, W.L., 2011. Photolysis of Enrofloxacin in aqueous systems under simulated sunlight irradiation: kinetics, mechanism and toxicity of photolysis products. Chemosphere 85, 892-897.

Li, Y., Niu, J., Shang, E., Zheng, M., Luan, T., 2014. Effects of nitrate and humic acid enrofloxacin photolysis in an aqueous system under three light condition: kinetics and mechanism. Environ. Chem. 11, 333-340.

Li, T., Kim, B.B., Ha, T.H., Shin, Y.B., Kim, M.G., 2015. The effects of pH and surfactants on the absorption and fluorescence properties of ochratoxin A and zearalenone. Luminescence 30, 1106-1111.

Lin, A., Reinhard, M., 2005. Photodegradation of common environmental pharmaceuticals and estrogens in river water. Environ. Toxicol. Chem. 24, 1303-1309.

Liu, G.M., Zheng, S.R., Xing, X.L., Li, Y.F., Yin, D.Q., Ding, Y.S., Pang, W.H., 2010. Fe(III)oxalate complexes mediated photolysis of aqueous alkylphenol ethoxylates under simulated sunlight conditions. Chemosphere 78, 402-408.

Massart, F., Meucci, V., Saggese, G., Soldani, G., 2008. High growth rate of girls with precocious puberty exposed to estrogenic mycotoxins. J. Pediatr. 152, 690-695.

Muñoz, L., Castro, J.L., Cardelle, M., Castedo, L., Riguera, R., 1989. Acetylated mycotoxins from Fusarium graminearum. Phytochemistry 28, 83-85.

Neamtu, M., Frimmel, F.H., 2006. Photodegradation of endocrine disrupting chemical nonylphenol by simulated solar UV-irradiation. Sci. Total Environ. 369, 295-306.

Peters, C.A., 1972. Photochemistry of zearalenone and its derivatives. J. Med. Chem. $15,867-868$.

Qu, S., Kolodziej, E.P., Cwiertny, D.M., 2012. Phototransformation rates and mechanisms for synthetic hormone growth promoters used in animal agriculture. 
Environ. Sci. Technol. 46, 13202-13211.

Richardson, K.E., Hagler, W.M., Mirocha, C.J. 1985. Production of zearalenone, $\alpha$ - and $\beta$-zearalenol, and $\alpha$ - and $\beta$-zearalanol by Fusarium spp. in rice culture. J. Agric. Food Chem. 33, 862-866.

Ryu, D., Hanna, M.A., Eskridge, K.M., Bullerman, L.B., 2003. Heat stability of zearalenone in an aqueous buffered model system. J. Agric. Food Chem. 51, 1746-1748.

Schenzel, J., Hungerbühler, K., Bucheli, T.D., 2012. Mycotoxins in the environment: II. Occurrence and origin in Swiss river waters. Environ. Sci. Technol. 46, 13076-13084.

Schwartz, P., Thorpe, K.L., Bucheli, T., Wettstein, F.E., Burkhardt-Holm, P., 2010. Short-term exposure to the environmentally relevant estrogenicmycotoxin zearalenone impairs reproduction in fish. Sci. Total Environ. 409, 326-333.
Sforza, S., Dall'Asta, C., Marchelli, R., 2006. Recent advances in mycotoxin determination in food and feed by hyphenated chromatographic techniques/mass spectrometry. Mass Spec. 25, 54-76.

Zhan, M., 2009. Determination of photochemically-generated reactive oxygen species in natural water. J. Environ. Sci. 21, 303-306.

Zhou, D., Wu, F., Deng, N., 2004. Fe(III)-oxalate complexes induced photooxidation of diethylstilbestrol in water. Chemosphere 57, 283-291.

Zhou, C., Chen, J., Xie, Q., Wei, X., Zhang, Y.-N., Fu, Z., 2015. Photolysis of three antiviral drugs acyclovir, zidovudine and lamivudine in surface freshwater and seawater. Chemosphere 138, 792-797.

Zinedine, A., Soriano, J.M., Moltó, J.C., Mañés, J., 2007. Review on the toxicity, occurrence, metabolism, detoxification, regulations and intake of zearalenone: an oestrogenic mycotoxin. Food Chem. Toxicol. 45, 1-18. 